\title{
Exploratory research on course teaching of architectural design based on ability cultivation of practice and innovation - Take course teaching of high-rise building design as an example
}

\author{
Ming Gao \\ School of Civil Engineering and Architecture, Southwest University of Science and Technology, Mianyang, Si- \\ chuan, China
}

\begin{abstract}
Under current disciplinary development reform and the objective of strengthening ability cultivation of practice innovation, this thesis makes comprehensive analysis of the problems existing in "high-rise building design" teaching for undergraduates majoring in architecture; and proposes new philosophies of focusing on teaching process, opening up joint school management and research-oriented teaching in combination of construction transformation demands. Based on the above background, this thesis also proposes the teaching conception of establishing multi-platform frame. Moreover, it discusses corresponding platform establishment and teaching design in combination of educational reform practice.
\end{abstract}

Keywords: practice innovation; ability cultivation; teaching philosophy; high-rise building design teaching

At present, our educational policy emphasizes on cultivating practice ability, and has written quality-oriented education into law. Design course teaching in architecture major shall enhance student's ability cultivation. As architecture education workers, we have found through reflection that although we have an "improved teaching system" including teaching objectives, teaching method and process, teaching content, teaching principles, and teaching assessment, the teaching idea of cultivating student's design ability is still vague. Previous key teaching point focuses on enhancing design result. The teaching mode is "teachers teaching by personal examples as well as verbal instruction" which is one-sided and rigid. The teaching method is dull and passive teaching in which "students listen to teachers and watch how teachers modify design drafts". Little emphasis has been attached on student's exploratory study of design and achievement obtained during study. According to the condition that current teaching situation cannot adapt to the objective and requirement of strengthening student's ability cultivation, this thesis explores the teaching reform of "high-rise building design" curriculum for the $4^{\text {th }}$ grade; and discusses the idea of reform and innovation.

\section{TEACHING OVERVIEW}

"High-rise building design" is a main course for architecture major in department of civil engineering and architecture of Southwest University of Science and Technology. It is set in the first semester for undergraduate students in the $4^{\text {th }}$ grade. Students in this grade have gained certain design ability with individual thinking; and are able to interact with teachers during design process and express their understandings. In this period, the teaching relation is no longer the "master and apprentice relationship" in lower grades. With knowledge enlargement and more chances to participate in social practice, students can understand the working procedures and design methods of designing institutes faster and adapt to social needs as soon as possible after obtaining employment. Start from analyzing urban integrality and environmental coordination, course teaching aims to create harmonious coexistence with surrounding environment in a higher angle of view and a larger spatial scale. It helps students to think how architects can emphasize on environment and pursue sustainable development which has become a higher-level objective while following basic principles of space, form, scientific technology and disaster prevention with 
discretion, rationality, responsibility and artistic originality.

\section{TEACHING SITUATION AND PROBLEMS}

High-rise architecture is synthesis with multi-disciplines and complicated technologies of which the teaching includes: site environment, function, traffic, model, structure, and equipment. During early teaching stage, although students have learned related professional knowledge, they are still lack of understanding of the complexity in high-rise architectural technologies and the cooperative coordination among each profession. Generally, it is hard to make synchronized arrangement of teaching progress. After previous exploration, both teachers and students can be exhausted and generate a situation of "tense at first and relax later" in teaching and learning. In later phase of designing, students always stay up for drawing and it's not hard to imagine how the drawing quality can be.

Moreover, there're many problems need to be discussed in design course itself. The setting of design course in architecture has always applied a teaching method based on type architecture which is to help students get access to more design types as much as possible in their five-year design course. The teaching starts from simple types and develop to complicated ones. By covering architectural types as many as possible and arranging a great deal of repeated training, students are required to master the features and design methods of each architectural type. It is an empirical teaching system and has brought problems in the following parts:

(1) Communication and discussion in class

The course mode follows the teaching mode applied in lower grades. Design assignment book is issued in the first theory class. Students are asked to collect related reference materials, conduct on-the-site surveys, make PPT presentation, and submit written reports in groups. Teachers review the repots and make collective assessment. Then, students begin to draw the first draft, the second draft, and the third draft in the class. At last, they must complete front elevation and experience the overall process of public design evaluation. In general, students' survey reports are vague in content and lack in targeted independent thinking. Their homework is formalistic and can offer little help to effectively deepen following architectural scheme concept. In addition, communication between teachers and students is difficult in the class. Most students are lack of language expression ability to show their ideas about design. It is hard for them to use language expressed in drawings to manifest their design ideas and concepts. In most cases, teachers have to guess their students' ideas and offer guidance on designing. Thus, few students are able to design a good work.
(2) Professional skills \& laws and regulations

Architectural design is to find the optimal scheme with limitation in environment, site, laws and regulations, and society. However, it can be seen from students' design drawings that some students frequently pay little attention to architectural specifications and basic design principles. They are random in design and make no further analysis. In this kind of designs, it's rare to find enough thinking on social application, economic cost, and energy conservation. Some designs are only equipped with building lines can barely satisfy the needs of fire control. As the building lines in these design schemes go against regulations, it is impossible to realize the designs and direct influence can be left on deepening designs and the quality of the final results.

(3) Neglect on architectural technology

The objective of selecting high-rise building design as the topic is to enhance the comprehensive application of knowledge in each profession. Problems of emphasizing architectural functions and modeling designs and neglecting structure, water supply, electricity supply, heating and ventilation exist among students and teachers. Students know little about the application of other professional knowledge in designing. Some may even know nothing about it. While facing large-scale complex subjects, many students are lack of ability equal to their ambition and fail to find a clue. Thus, the results tend to be failure of designing depth to meet the depth required in actual engineering demand.

(4) Design methods and front elevation presentation In teaching, it has been found that part students' designs are disordered in designing steps. Those students always plagiarize effect pictures or data drawings from library or websites about architecture. The one-sided trend of pursuing fashion and neglecting site limitation will only lead to low-quality design results. In front elevation presentation, some students pay too much attention to visual effect but too little attention to logical directional diagram. Those students always focus on how to make the drawings colorful instead of presenting depth and drawing normalization. In some cases, important steps are neglected, such as deliberation, analysis, evolvement, and generation of design process. It's easy for students to make many mistakes in section presentation, leaving direct influence on student's professional development and employment quality.

\section{ANALYSIS AND CONSIDERATION}

After entering design industry, graduates will face architectural types more than those involved in university courses. As long as they have enough logical thinking ability and qualified professional basis, most students can solve common problems they have in 
practical architectural work. That focus on complicated functional design attached by universities can lead to similar topics and ideas in architectural design courses. Therefore, the effective and practical countermeasure is to establish a close relation between course topic and practice on one hand; and cultivate student's strict attitude in designing on the other hand.

Architectural design shall be able to analyze problems and solve problems. While facing various contradictions in actual engineering projects, students must make analysis and extensively listen to all professional suggestions. To integrate various relations inside one building in an orderly and complete way, students need to be strict and precise in designing. Many students' architectural schemes focus on the "art" in form, but are lack of in-depth thinking and analysis. Their understandings of architectural space and plane reasonability are rough; not to mention how much they know about architectural technical characters, social factors, and economic factors. That is to say, there are great deficiencies of the ability to deepen designs among students.

Furthermore, students' homework can manifest their problems of working attitude and design concept. Much excellent homework contains forms in close relation with environment. From plane, space to form, an architectural design shall be in an integral and in-depth system full of logic and rationality instead of randomness. To meet this requirement is different from student's sloppy simulation of masters' works. How to cultivate students to develop a habit of strict thinking during designing is a question worthy great attention. In employment, graduates need to be strict and precise at work and have the ability of designing in-depth works to cope with a large number of actual engineering projects. In order to reach such teaching goals, depth of design must be deepened. No more work for appearance sake is needed. In this way, students have to be strict and precise about their designs so as to complete the added quantity in drawing.

A set of strict high-rise building design ideas must be established to meet the needs required in teaching features. Current educational system for architecture is too simple. Most universities and colleges are still following the teaching system of "type architecture" which is out of proportion to the rapid development of architecture industry nowadays. After graduation, most students will become surefooted architects. However, the basic quality requirements set in architect practice need architects to be rational and precise.

\section{TEACHING PRACTICE}

Based on the thinking described above, corresponding measures can be taken in teaching of "high-rise architectural design" so as to develop in-depth design and establish precise working style. At first, emphasize on the teaching process aiming at ability cultivation. Take research-oriented teaching as the mainline. Establish new understandings and conceptions of teaching objective, teaching content, teaching principles, and teaching methods according to reflection on previous course teaching. Teaching reform mainly includes the following parts.

\subsection{Diverse and open-type topic setting}

All design topics use real subjects with real terrains so as to reduce the complexity of function streamline and focus on deepening design. According to the standard requirements set in education assessment on architecture major in national institutions of higher education, the whole teaching faculty have considered the research orientation, timeliness or features of topic through discussions about topic direction, site selection, type, scale, space, process control, and standards for evaluation. Design topic shall emphasize on system integration and fully arouse student's enthusiasm of learning.

Six areas are set for the teaching subject of "architecture and cities": urban design, bank office building, high-rise commercial and residential complex, comprehensive office building for city hotel, ecological green architecture, and parameterized architectural design. Students can make independent choices according to their teachers' research subjects and participated practice engineering projects (see Figure 1).

\subsection{Teaching methods of innovation unitization, modularization, and diversification}

Divide the entire course teaching into several independent modules. Each knowledge module shall have one topic, such as function division, transportation streamline, architectural structure, high-rise fire protection, and mechanical equipment, etc. Firstly, give theory explanation through PPT, conduct case analysis, and organize Q\&A discussion. Then, give deeper explanation according to each independent question. In this way, students can have partitioned training to solve a series of detailed problems about high-rise building and accomplish comprehensive integration based on their understandings of professional knowledge related to high-rise building design.

Hire senior architects and chief engineers from design organizations to teach knowledge about structure and utilities. According to different topic directions, teachers in each teaching group can organize lectures on special topics based on their own specialties: Introduction to high-rise building: 1) progress, definition classification, relations with cities; and analysis of classic cases. 2) Architectural technology: structural system, underground garage, equipment room, core tube, and refuge storey. 3) Historical context: influence and value in culture, society, and historical background. 4) Specification carding: familiar with laws and regulations of all kinds of countries, and practical 


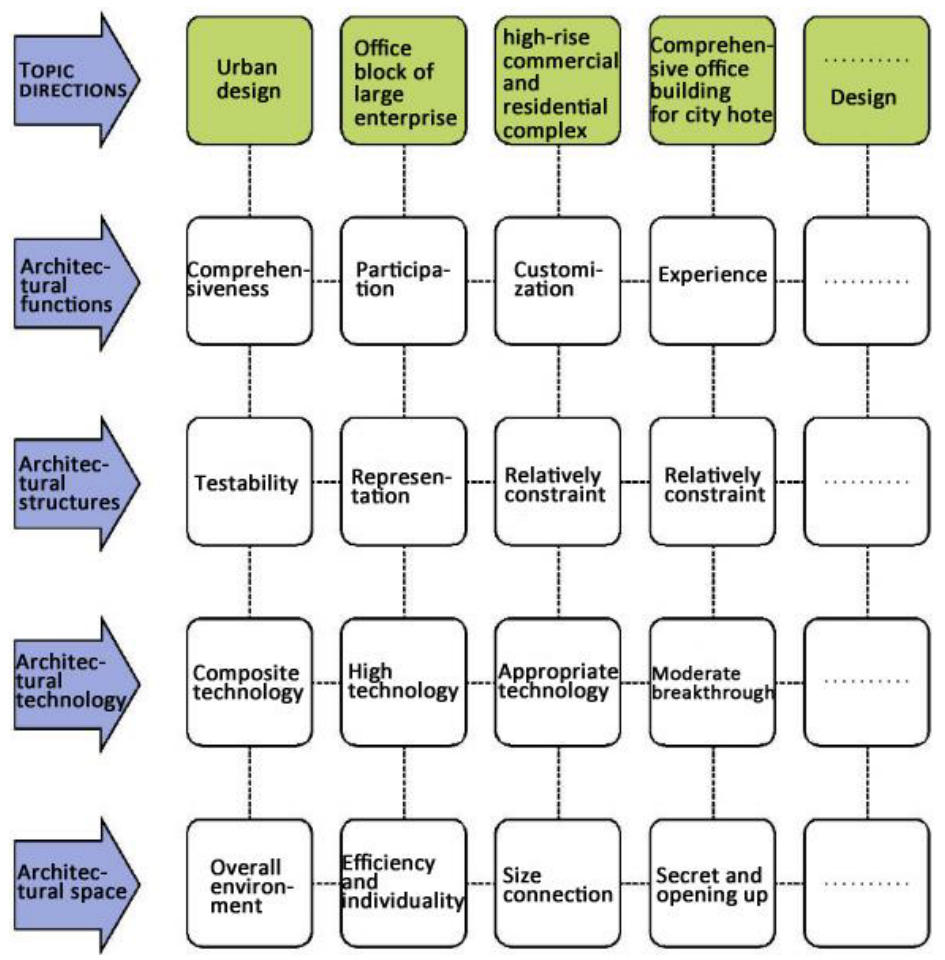

Figure 1. Matrix graph of "high-rise building design" topic

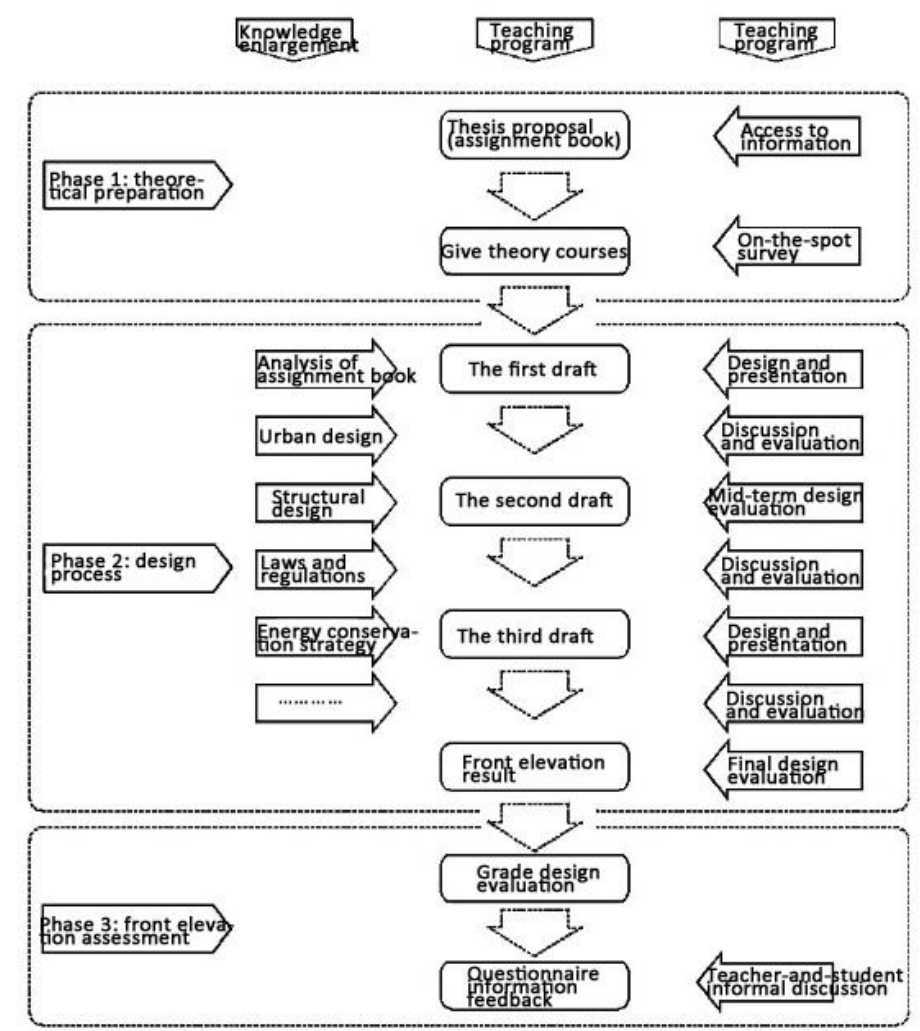

Figure 2. Frame diagram of "high-rise architectural design" curriculum teaching structure

requirements of construction units. Help students obtain practical experience before scheme design and make them know fairly well.

Use heuristic teaching, discussion teaching, participative teaching, research-oriented study, and other teaching methods in theory teaching, in order to effectively arouse students' enthusiasm of learning; promote their positive thinking; arouse their potential; and lead them to self-study. A large number of visualized teaching means are required in design theory 
teaching. Slide show, projection, and multimedia courseware can be used while electronic lectures and multimedia teaching method can be popularized.

\subsection{Emphasis on process and operational ability}

We have set up a series of strict and compact teaching systems. In previous graduation design, only the first draft, the second draft, front elevation draft and front elevation were required. This mode has to be changed so as to emphasize on reasonable logic and theoretical foundation in design. According to the "tense at first and relax later" phenomenon in student's learning, students are asked to conduct on-the-site survey and research analysis firstly. Then, they shall draw analysis graphical representation and explanation which should be objective as much as possible and avoid personal value orientation. Moreover, students need to collect classic architectural examples at home and abroad; and use PPT to make analysis assessment. According to the interest points in their assignment books, students need to accomplish extensive reading and conclude their points of view for teachers to review. While compiling the design research report of the second draft, students need to analyze and discuss their architectural scheme concepts; and actively cooperate with architectural technical group. The establishment of the method combing teaching and individual coaching can build close contact with practice and lead students to be realistic and strict in design.

In each phase of the entire design process, student shall comprehensively compare several schemes according to different requirements (including requirements of construction side). They shall explain the orderly whole constituting their entire designs in forms of different drafts and documents, such as concept sketch, free-hand sketch, instrument draft, formal drawing, and engineering documents. Awareness of integrity shall play a leading role all the time. While solving a problem in high-rise building design (initial stage), such as function use or traffic organization, students are allowed to have inadequacy in molding, structure, equipment and other parts. Moreover, students shall try to integrate several schemes based on one scheme; take the work completed in previous phases as precondition; continuously make self- examination on previous work; and deepen their understanding of mistakes, in order to maintain the continuity of the entire scheme and develop integral consciousness of scheme design (as shown in Figure 2).

Training of student's ability in making manual architectural body pattern is emphasized during teaching process. Discussion about architectural artistic aesthetics and analysis of relations between architectural body and site and between architecture and urban environment can be directly reflected by models. We try to deepen student's ability to use SU three-dimensional modeling technology and virtual technology to analyze spatial forms inside and outside buildings; lead students to emphasize on design means which apply new technologies to simulate reality. Supplement, update, extension, and quotation of classic engineering cases and research achievements obtained at home and abroad are organized in classroom discussion. Common problems in design can be solved by comparison and analysis of multiple cases.

\subsection{Classroom communication and teamwork}

We try to help every student actively participate in classroom statement and discussion. Teachers can understand students' design thoughts by observing and listening to their speeches. By analyzing defects and error made in design consideration, teachers can propose appropriate measures to rectify and reform. The expression of each student's design thoughts can be information source for other students. Mutual reference and comparison about design thoughts among students can enrich information of design teaching and strengthen student's judging ability of independent thinking while facing a problem.

Innovative two-way selection mode is applied in course teaching. Students can choose course title and teachers through online course selection system. One teacher is responsible for 10 or more students as a group. Group members shall cooperate. Discussion and reports are made among different groups. Homework related with design is given in the class and publicly discussed in the next class. In this way, defective condition that class hours were used for drawing or designing in the past can be changed. Teaching order that students think and prepare after class; make conclusions before class; and report and discuss in the class can be established. Previous situation in which design teachers only played a role of consultant can also be changed. In group assessment after class, students are asked to make corresponding design conclusions and rethink their gains and losses in the class. They shall also provide suggestions for teacher's teaching method and fill in after-class feedback questionnaire.

\subsection{Practice of architect's participation and design evaluation}

We pay much attention to cultivation of engineering technology and practice ability. Our course teaching relies on practice project and includes practice research into class teaching. We hire architects with good reputation from local designing institutions to be our course "tutors". They participate in the setting and guidance of the entire design course. We also hire structural engineers and equipment engineers to teach related basic knowledge. They can offer detailed guidance for problems of structure and equipment existing in design and combine representative instances. The engineers and teachers introduce what they focus on in the classroom and students can gain 
more access to knowledge that is not covered in the education system. Through the whole process of course teaching, students can feel the real design atmosphere and participate in design and technical problem solution of real project so as to improve their ability of solving practical problems.

The "large-scale design evaluation" applied in this course is an effective means to enrich and strengthen design teaching. We changed the previous "closeddoor design evaluation" into "open-door design evaluation". We hire well-known architects and experts to participate in final design evaluation. Focusing on strictness and preciseness of design result introduction they can provide different design concepts and evaluation angles and beneficial complement of design teaching system. We have established a clear and orderly resultant design review system and open result evaluation standards. Design result evaluation can fairly reflect student's actual design ability. During teaching, we encourage students to take part in international and domestic design competitions, in order to enrich interdisciplinarity and challenge in teaching.

\section{TEACHING REFLECTION AND CONCLUSIONS}

Our department has gradually made reform in the teaching content and teaching method in architectural design course. During teaching process, we focus on the combination of designing ability and practice; and try to integrate innovation and cultivation of practice ability. Process and details should be emphasized on in teaching and there're many other problems require further thinking and improvement in teaching.

\subsection{In combination of practice diversification and opening up}

In teaching, we innovate to enhance the diversification and opening-up of our teaching concept and teaching method which can be reflected not only in the condition that students can make their own choices in topic and teacher selections; but also in the cooperation with designing units, the owners, and construction management department. Cooperation shall run through the overall process of course design.

\subsection{Based on cultivation of comprehensive abilities}

Architects shall have multi-specialty knowledge and comprehensive quality. We emphasize on improving student's comprehensive ability, including related knowledge, professional skills, and employment capability. We not only focus on offer training about architectural skills and related professional knowledge; but also enhance the application of three-dimensional animation of dynamic simulation made by design software such as su, lumion, and max in design result presentation and student's manual practice ability of making models. In the meantime, topic group leaders can assist teachers to arrange group issues and coordinate to organize lectures and scheme seminars inside and outside the campus. In this way, students can improve their personal organizational management ability and obtain more chances to build teamwork with classmates.

\subsection{Authenticity and innovation of topic}

The information content covered in a real topic cannot be compared by a fake one. Conducting all-round survey and research according to factors such as foundation and users is very important in establishing a design concept. Students shall be able to face complex environment, situation, and traffic conditions. After receiving a task, they shall investigate terrain environment at first. This step can prevent them from developing random design from nowhere. Meanwhile, topic selection shall accord with the standard requirements set in professional education evaluation for architecture major in national institutions of higher education. Ecological green architecture and parameterized design shall be included for innovation.

\subsection{Deepening design results}

According to requirements set in assignment book, more drawings should be added besides the originally regulated planes of each floor, four elevations, and a section drawing. Certain quantity of part planes, elevations and sections shall be regulated and more weight should be attached to analysis graphics. Students shall also be asked to answer more detailed questions such as the reason for them to make such designs. Introduce other professions for orderly cooperation. Ask students to draw sections which can show clear presentation structures and relations of architectural space. They shall be able to cope with influence left by equipment pipeline direction on architectural space. Students shall also be required to draw part architectural details and structural node details.

With further deepening of course teaching reform, we hope our teaching system can be in gradual improvement. We will pay a return visit to employers and students and collect their suggestions on architectural design topic selection and process by issuing questionnaires. According to the collected feedback information, we will make conclusions and continue our improvement on teaching in the future.

\section{ACKNOWLEDGEMENT}

This paper is funded by the 2014 Research Project of Education and Teaching Reform of Southwest University of Science and Technology (Project No.: 14xn0094). 


\section{REFERENCES}

[1] He, K.K. 1997. Teaching model, teaching method and teaching design of constructivism. Journal of Beijing Normal University (Social Science Edition), (5).

[2] Zhuo, G. 2011. High-Rise Building Design. Wuhan: Huazhong University of Science and Technology Press.

[3] Kenneth F. 2007. Studies of Tectonic Culture-Discussion on the Constructional Peotics in $19^{\text {th }}$ Century and $20^{\text {th }}$ Century Buildings (Translated by Wang, J.Y.). Beijing: China Architecture and Industry Press.
[4] Yang, Y.Z. 2009. Building types and teaching dimensions--Teaching notes of high-rise building design course. New Architecture, (4).

[5] Gong, K. 2005. Research on the building design teaching for the $4^{\text {th }}$ Grade of department of architecture in Southeast University. Architectural Journal, (12).

[6] Zhang, L. \& Liu, J.P. 2014. Teaching research on green building design. Building Science Research of Sichuan, (4). 